ORIGINAL ARTICLE

\title{
Physicians' opinions about partner notification methods: case reporting, patient referral, and provider referral
}

\author{
M Hogben, J S St Lawrence, D E Montaño, D Kasprzyk, J S Leichliter, W R Phillips
}

Sex Transm Infect 2004;80:30-34. doi: 10.1136/sti.2003.004937

See end of article for authors' affiliations

.....................

Correspondence to:

Dr Matthew Hogben,

Centers for Disease

Control and Prevention,

Mail Stop E-44, 1600

Clifton Road, Atlanta, GA

30333, USA

mhogben@cdc.gov

Accepted for publication 7 July 2003

\begin{abstract}
Background: The United States has relied upon partner notification strategies to help break the chain of infection and re-infection for sexually transmitted diseases (STD). Physicians are a vital link in the system of STD control, but little is known of physician opinions about partner notification strategies.

Methods: We collected opinions about partner notification from a national probability sample of physicians in specialties diagnosing STDs. Physicians responded to 17 questions about three relevant forms of STD partner notification: patient based referral, provider based referral, and case reporting.

Results: Exploratory factor analyses showed that responses for each form of partner notification could be grouped into four categories: perceived practice norms, infection control, patient relationships, and time/ money. Multivariate analyses of the factors showed that physicians endorsed patient based referral most favourably and provider based referral least favourably.

Conclusion: Physicians' opinions about partner notification strategies appear to reflect objective reality in some areas, but not in others. Strategies that improve the fit between physicians' opinions and effective notification are needed: some are discussed here.
\end{abstract}

n the United States, many sexually transmitted diseases (STDs) continue to represent a significant disease burden and public health challenge. ${ }^{1}$ In part, the problem is sustained because many infected people remain untreated and even unaware of their infections. Partner notification is a public health strategy that, by successfully notifying partners of people diagnosed with STDs that they have been exposed to an infectious disease and encouraging them to seek medical evaluation, disrupts the cycle of infection and reinfection. Techniques aimed at convincing the infected person to notify sex partners of their exposure fall under the rubric of "patient referral." Mechanisms through which a professional (usually a disease intervention specialist: DIS) interviews the infected person to elicit names of sex partners and then notifies those partners are called "provider referral." In both instances, referral means that someone (a provider, an infected person) is referring sex partners to some place to get evaluated and treated. Finally, case reporting by physicians to health departments can set in motion either form of partner notification.

There is substantial variance among studies of the effectiveness of partner notification strategies, but metaanalytical studies suggest that provider referral in the public sector identifies the most infected individuals. ${ }^{2}{ }^{3}$ However, STDs are not treated exclusively, or even predominantly, in the public sector. ${ }^{4}$ Consequently, more of the onus for partner notification falls upon the private sector than is generally reflected in the research literature. By uncovering aspects of partner notification that private, as well as public, physicians consider barriers and by comparing their responses across the three different partner notification strategies, we may uncover reasons why deficiencies exist and inform interventions aiming to increase the usefulness of partner notification techniques.

\section{METHODS}

\section{Participants and procedure}

We sampled 7300 physicians in five specialties (obstetrics/ gynaecology, internal medicine, general/family practice, emergency medicine, paediatrics) from the American
Medical Association's Physician's Master File. Physicians in these five specialties treat $85 \%$ of all STDs in the United States. ${ }^{5}{ }^{6}$ Eligibility criteria were that the physicians spend at least $50 \%$ of their time in direct patient care and that they saw patients between the ages of 13 and 60 years. Surveys, cover letters, and \$15.00 were delivered via Federal Express, with reminder postcards following, if needed. The final response rate was $70.2 \%$ (4223 surveys).

\section{Materials}

We solicited 17 opinions about types of partner notification, with content for those questions drawn from focus group interviews with physicians. Responses to each item, assessed on five point Likert scales ( $1=$ "strongly disagree," $2=$ "disagree," 3 = "neutral," 4 = "agree," $5=$ =strongly agree"), follow from each of three stems, representing case reporting, patient referral, and provider referral. The full stems were:

- Reporting patients to the health department for follow up... (case reporting, CR)

- Encouraging your STD patients to contact their partner(s) themselves... (patient referral, PaR)

- Collecting the names of partner(s) of STD patients and contacting them directly... (provider referral, PrR)

For example, a physician responding to the first item in table 1 with the first stem indicated some level of agreement with the full statement: "Reporting patients to the Health Department for follow up complies with the standard of care in my clinic."

\section{Analysis plan}

We aimed to (1) describe the range of physician opinions with respect to partner notification practices, (2) present a parsimonious account of such variables, and (3) outline how endorsement of opinions might vary with the type of partner notification practice. Item means and standard deviations sufficed for the first aim. For the second, we turned to exploratory factor analysis (EFA) to help us group related opinions into a smaller number of factors, each of which 
Table 1 Means and standard deviations for item responses by type of notification

\begin{tabular}{|c|c|c|c|c|c|c|}
\hline & \multicolumn{2}{|c|}{ Case reporting } & \multicolumn{2}{|c|}{ Patient referral } & \multicolumn{2}{|c|}{ Provider referral } \\
\hline & Mean & SD & Mean & SD & Mean & SD \\
\hline $\begin{array}{l}\text { (1) Complies with clinic standard of } \\
\text { care }\end{array}$ & 3.61 & 0.9 & 3.77 & 0.9 & 2.74 & 0.9 \\
\hline (2) What most of my colleagues do & 3.25 & 1.0 & 3.47 & 0.8 & 2.46 & 0.9 \\
\hline (3) Expected by my health department & +3.69 & 0.9 & 3.56 & 0.8 & 2.79 & 1.0 \\
\hline (4) Valued in my clinic setting & 3.37 & 1.0 & 3.81 & 0.8 & 2.81 & 0.9 \\
\hline (5) I don't feel comfortable & 2.54 & 1.2 & 2.08 & 0.9 & 3.48 & 1.1 \\
\hline (6) I don't feel well trained & 2.51 & 1.1 & 2.28 & 0.9 & 3.09 & 1.0 \\
\hline (7) Causes my patients not to return & 2.67 & 1.0 & 2.29 & 0.8 & 3.12 & 1.0 \\
\hline (8) Gets the patient upset with me & 3.01 & 1.0 & 2.29 & 0.8 & 3.38 & 1.0 \\
\hline (9) Not my responsibility & 2.27 & 1.0 & 1.97 & 0.8 & 3.14 & 1.0 \\
\hline (10) Help prevent spread of STD & 4.16 & 0.9 & 4.08 & 0.8 & 3.66 & 1.0 \\
\hline (11) Fulfil my "duty to warn" & 3.81 & 0.9 & 3.67 & 0.9 & 3.40 & 1.0 \\
\hline $\begin{array}{l}\text { (12) Protects my patients from re- } \\
\text { infection }\end{array}$ & 3.58 & 1.1 & 3.66 & 1.0 & 3.42 & 1.0 \\
\hline $\begin{array}{l}\text { (13) Opportunity for prevention } \\
\text { education }\end{array}$ & 4.01 & 0.8 & 4.13 & 0.7 & 3.72 & 0.8 \\
\hline $\begin{array}{l}\text { (14) Helps patients change their risk } \\
\text { behaviour }\end{array}$ & 3.18 & 1.1 & 3.42 & 1.0 & 3.11 & 1.0 \\
\hline (15) Take too much of my time & 2.82 & 1.1 & 2.12 & 0.9 & 3.73 & 1.0 \\
\hline (16) Take too much staff time & 2.80 & 1.2 & 2.18 & 0.9 & 3.72 & 1.0 \\
\hline (17) An activity I won't get paid for & 3.57 & 1.1 & 3.28 & 1.1 & 3.72 & 1.0 \\
\hline
\end{tabular}

comprised several items. Interpretable factors comprising multiple items have the advantage of conveying clear meaning with a single score. To discern whether physicians differed in how they endorsed partner notification strategies we ran a repeated measures multivariate analysis of variance (MANOVA) with univariate follow up tests, using the different types of partner notification (case reporting, patient referral, provider referral) as a repeated measures grouping variable, and physician scores on scales derived from the EFA as the outcome variables. Where relevant items were recoded such that agreement implies endorsement.

\section{RESULTS}

\section{Sample}

Demographically, the physician sample is representative of physicians in the United States. Physicians' mean age was 46.2 years (SD 10.3), with 2953 (70.9\%) male respondents and $1214(29.1 \%)$ female respondents. Physicians had been practising for a mean of 17.8 years (SD 10.5), spending an average of 42.7 hours per week (SD 16.7) in direct patient care. Most physicians saw a variety of patients, but estimated the majority of patients (62.6\%) were female. Approximately two out of three physicians were in a primary care office, with most of the remainder working in a hospital environment (including emergency rooms, urgent care hospital clinics, and ambulatory care facilities). Most physicians (86.7\%) have diagnosed at least one STD in the previous year, and most (87.1-88.1\%) indicated they diagnosed each of the most common bacterial STDs, chlamydial infections, and gonorrhoea. Further information is available in the paper by St Lawrence et al.?

\section{Physician opinions concerning partner notification strategies}

Physician responses to the 17 individual questions are contained within table 1 . The smallest mean difference between any two comparisons is 0.07 points (CR versus PrR on question 14), and this difference is significant at $\mathrm{p}<0.001$. This significance level is maintained in the face of a Bonferroni adjustment for the 42 possible comparisons so, in short, scores on the variables all differ statistically from one another.
Depending on the STD, 38.5-49.6\% of physicians always reported patient names to health departments. The corresponding figures for "usually" were $11.2-11.9 \%$, with $28.3-$ $36.3 \%$ never reporting cases. Most (80.8-83.8\%) always asked their patients to notify their partners (usually $=12.5-14.4 \%$; never $=1.4-1.5 \%$ ). However, only $4.1-4.4 \%$ of physicians always practised provider referral (usually $=3.9-4.3 \%$; never $=71.6-71.8 \%)$.

Over half the physicians (57.3\%) agreed or strongly agreed that case reporting to health departments complied with their clinics' standards of care and that doing so fulfilled any duty to warn $(70.5 \%)$. Physicians also viewed case reporting as a relatively effective means of controlling STD, with $81.5 \%$ agreeing or strongly agreeing that case reporting presented an opportunity for prevention education, and $40.7 \%$ agreeing or strongly agreeing that case reporting helped patients change their risk behaviours (versus $27.6 \%$ disagreeing or strongly disagreeing) and helped prevent the spread of STD (82.7\%). Physicians were neutral about whether case reporting consumed too much of their time $(\mathrm{M}=2.82)$ or their staffs' time $(M=2.80)$.

Physicians were about as sanguine about the effects of patient referral. More physicians (70.1\%) agreed or strongly agreed that patient referral complied with their clinics' standards of care, although somewhat fewer (67.4\%) considered that doing so fulfilled a duty to warn. Physicians also viewed patient referral as about as effective as case reporting at controlling STD. Similar percentages of respondents agreed or strongly agreed that patient referral presented an opportunity for prevention education $(89.7 \%)$, helped patients change their risk behaviours $(51.9 \%)$, and helped prevent the spread of STDs (83.5\%). Physicians, on the whole, disagreed with the idea that patient referral would be too time consuming for them $(M=2.12)$ or their staff $(\mathrm{M}=2.18)$.

More physicians disagreed $(41.4 \%)$ than agreed $(18.9 \%)$ that provider referral met their clinics' standards of care, although a majority (51.0\% agreed/strongly agreed) felt that provider referral fulfilled a duty to warn. Although physicians agreed that provider referral was of some benefit in controlling STDs, fewer physicians than in either of the above two conditions considered provider referral an opportunity for prevention education $(69.7 \%$ agreed/strongly 
agreed), a help to changing patient risk behaviour (37.7\%), or a help to preventing the spread of STDs $(66.7 \%)$. Moreover, physicians were much more likely to feel that provider referral would be overly time consuming for both themselves $(M=3.73)$ and their staff $(M=3.72)$.

\section{Exploratory factor analyses (EFA)}

We subjected the 17 items to three principal components analyses (one for each PN strategy), which yielded four factors (components) for each (table 2). We then rotated the factors, using the varimax procedure to improve interpretability.

The four factors together accounted for $62 \%$ of the total variance among the 17 items for case reporting (CR), 57.5\% for patient referral (PaR), and $64.4 \%$ of the variance for provider referral (PrR). These percentages are similar enough to one another to suggest that results represent physicians' responses to the 17 items equivalently for each type of partner notification strategy. Factor I represented physician norms for good service ("norms"), factor II, the importance of maintaining good relations with patients ("patient relations"), factor III, the importance of STD control ("infection control"), and factor IV, the effects of time and money ("time/money").

Item factor correlations (that is, factor loadings) are contained in table 2, with the largest loading for each item marked in bold. On almost every occasion, each item loaded onto the same factor for each of the three forms of referral. Of the 51 conceptually important loadings listed in table 2 (those in bold), only five loaded naturally onto different factors. The only two anomalous loadings of any magnitude were time concerns (both physician and staff time), which, for PaR, loaded more strongly onto factor II than for factor IV. The alternative to using the PaR loadings for factor IV, however, is to use the loadings of both CR and PrR for factor II, which is more empirically problematic and conceptually less interpretable.
Scaling factors and differences among physicians by type of notification strategy

To compare physician attitudes formally on each factor by type of strategy, we created scales from each factor, summing items loading most strongly onto each factor into a single score (for example, factor I became a four item scale). Because items loaded onto the same factors for each type of strategy, we scaled the same items for each factor and thus made direct comparisons in a MANOVA framework. All but one scale had acceptable reliability according to conventional criteria. The $\alpha$ of 0.58 for PaR factor IV, (table 2) was lower, but we included factor IV in subsequent analyses.

In table 3, high means represent more favourable opinions about the scale content. A repeated measures MANOVA yielded a significant multivariate main effect for type of question, $\mathrm{F}(2,3767)=941.83, \mathrm{p}<0.001, \mathrm{R}=0.52$. This main effect showed that physicians had different opinions on the four scales depending on the type of partner notification strategy. Subsequent univariate ANOVA testing for differences by type of question for each scale individually revealed significant differences by type of partner notification strategy for each scale (see table 3). Furthermore, contrast testing among the groups revealed significant differences at each level of each outcome variable, all at $\mathrm{p}<0.001$ (a Bonferroni correction yields a criterion $p$ value of 0.004). Provider referral was uniformly rated least favourably and patient referral most favourably by physicians for each of the four factors.

\section{DISCUSSION}

Physician opinions about partner notification strategies are reducible to four areas, regardless of the particular notification strategy. Of the strategies, physicians think least of provider referral and think most of patient referral. In the remainder of this discussion, we assess these findings in terms of how they fit actual practice conditions (insofar as there are objective conditions), and then discuss how they might inform changes in partner notification practices.

Table 2 Factors describing physician opinions to partner notification

\begin{tabular}{|c|c|c|c|c|c|c|c|c|c|c|c|c|}
\hline & \multirow{2}{*}{\multicolumn{3}{|c|}{$\frac{\text { Factor I }}{\text { "Norms" }}$}} & \multirow{2}{*}{\multicolumn{3}{|c|}{$\begin{array}{l}\text { Factor II } \\
\text { "Patient relations" }\end{array}$}} & \multirow{2}{*}{\multicolumn{3}{|c|}{$\frac{\text { Factor III }}{\text { "Infection control" }}$}} & \multirow{2}{*}{\multicolumn{3}{|c|}{$\begin{array}{l}\text { Factor IV } \\
\text { "Time/money" }\end{array}$}} \\
\hline & & & & & & & & & & & & \\
\hline & CR & PaR & PrR & CR & PaR & PrR & CR & PaR & PrR & CR & PaR & PrR \\
\hline$\%$ of variance & 18.1 & 13.7 & 17.1 & 17.6 & 21.6 & 15.3 & 15.6 & 15.4 & 17.0 & 10.7 & 6.8 & 14.1 \\
\hline Reliability $(\alpha)$ & 0.86 & 0.74 & 0.83 & 0.83 & 0.79 & 0.79 & 0.75 & 0.74 & 0.80 & 0.67 & 0.58 & 0.82 \\
\hline $\begin{array}{l}\text { Complies with clinic standard of } \\
\text { care }\end{array}$ & 0.794 & 0.571 & 0.736 & -0.206 & -0.135 & -0.124 & 0.279 & 0.391 & 0.259 & -0.060 & -0.218 & -0.141 \\
\hline What most of my colleagues do & 0.785 & 0.736 & 0.786 & -0.187 & -0.189 & -0.140 & 0.185 & 0.100 & 0.010 & -0.109 & -0.015 & -0.135 \\
\hline $\begin{array}{l}\text { Expected by my health } \\
\text { department }\end{array}$ & 0.792 & 0.743 & 0.775 & -0.170 & -0.096 & -0.038 & 0.169 & 0.096 & -0.083 & -0.037 & 0.164 & -0.093 \\
\hline Valued in my clinic setting & 0.646 & 0.673 & 0.777 & -0.229 & -0.295 & -0.176 & 0.343 & 0.320 & 0.250 & -0.145 & -0.001 & -0.146 \\
\hline I don't feel comfortable & -0.273 & -0.216 & -0.256 & 0.772 & 0.671 & 0.690 & -0.082 & -0.070 & -0.071 & 0.124 & 0.171 & 0.257 \\
\hline I don't feel well trained & -0.197 & -0.208 & -0.189 & 0.717 & 0.592 & 0.576 & -0.012 & -0.032 & 0.010 & 0.112 & 0.298 & 0.194 \\
\hline Causes my patients not to return & -0.130 & -0.126 & -0.013 & 0.819 & 0.630 & 0.858 & -0.140 & -0.097 & -0.117 & 0.129 & 0.399 & 0.088 \\
\hline Gets the patient upset with me & -0.108 & -0.051 & -0.070 & 0.776 & 0.666 & 0.865 & -0.123 & 0.024 & -0.065 & 0.156 & 0.380 & 0.139 \\
\hline Not my responsibility & -0.421 & -0.235 & -0.479 & 0.404 & 0.593 & 0.335 & -0.250 & -0.219 & -0.236 & 0.348 & -0.085 & 0.352 \\
\hline Help prevent spread of STD & 0.206 & 0.182 & 0.064 & -0.203 & -0.101 & -0.046 & 0.676 & 0.711 & 0.776 & -0.025 & -0.044 & 0.001 \\
\hline Fulfil my "duty to warn" & 0.339 & 0.409 & 0.288 & -0.156 & 0.056 & -0.020 & 0.493 & 0.387 & 0.570 & 0.146 & -0.334 & 0.164 \\
\hline $\begin{array}{l}\text { Protects my patients from re- } \\
\text { infection }\end{array}$ & 0.091 & 0.149 & 0.069 & -0.103 & -0.013 & -0.021 & 0.764 & 0.778 & 0.804 & -0.074 & -0.118 & -0.104 \\
\hline $\begin{array}{l}\text { Opportunity for prevention } \\
\text { education }\end{array}$ & 0.213 & 0.249 & 0.160 & -0.129 & -0.234 & -0.108 & 0.679 & 0.622 & 0.739 & -0.058 & -0.030 & 0.010 \\
\hline $\begin{array}{l}\text { Helps patients change their risk } \\
\text { behaviour }\end{array}$ & 0.131 & -0.049 & 0.130 & 0.015 & -0.079 & -0.063 & 0.723 & 0.759 & 0.736 & -0.164 & -0.024 & -0.151 \\
\hline Takes too much of my time & -0.330 & -0.047 & -0.177 & 0.308 & 0.845 & 0.176 & 0.005 & -0.159 & -0.034 & 0.777 & -0.232 & 0.901 \\
\hline Takes too much staff time & -0.320 & -0.035 & -0.173 & 0.327 & 0.844 & 0.187 & -0.001 & -0.149 & -0.045 & 0.772 & -0.236 & 0.896 \\
\hline An activity I won't get paid for & 0.157 & 0.081 & -0.116 & 0.021 & 0.136 & 0.214 & -0.135 & -0.114 & -0.054 & 0.573 & 0.644 & 0.627 \\
\hline
\end{tabular}

$\mathrm{N}=3844$. $C R=$ case reporting; $\mathrm{PaR}=$ patient referral; $\mathrm{PrR}=$ provider referral. Percentage of variance refers to the proportion of variance accounted for by each factor (I-IV) for each variable (CR, PaR, PRR). Reliability refers to coefficient $\alpha$ (internal consistency) for each of the bold items defining the four factors (I-IV) across the three variables (CR, PaR, PRR). 
Table 3 Repeated measures multivariate analysis of variance of four scales

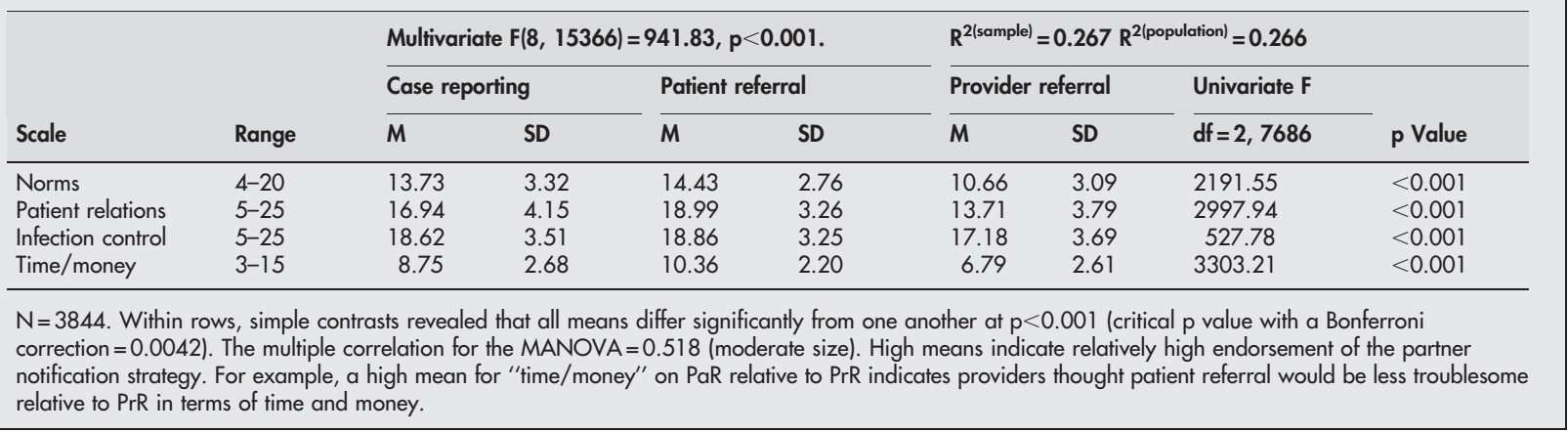

On one factor, time and money, physicians' opinions reflect objective conditions. Provider referral is more time consuming and consequently more expensive in terms of immediate costs, especially because neither doctors nor their staff are likely to be compensated. Provider referral may be more cost effective than other methods, but, at the time of choosing a partner notification method, the physician is faced with upfront costs, not the extended benefits.

Objective practice norms for partner notification are not easy to establish, largely because physicians are infrequently surveyed on the topic. Therefore, this paper essentially defines those norms and the factor represents them by definition. But do these specific norms reflect more general norms of service to patients? We look first at the relative scale scores on the factor "infection control." Physicians opined that patient referral was in fact a superior means of controlling STD to the other two methods, as shown in table 3. Although the difference in ratings was not very large, provider referral, when practised properly in the public sector, is substantially more effective at infection control. ${ }^{23}$ We cannot make the same assertion about provider referral as practised by private physicians because there are no US data, but the principle of a professional contributing to STD control by collecting sex partner information and notifying partners is established.

Do physicians feel provider referral is less effective than patient referral because they specifically feel unable to practise this strategy? Comparing provider referral to case reporting and patient referral, the item means in table 1 do reflect relative discomfort and a sense of being untrained. These items are also found in factor II, "patient relations." Physicians may rightly suspect that poor training and discomfort would produce an exchange that would upset patients and cause them not to return. There is also the question of physicians' perceptions that provider referral is inherently offputting to patients. This latter perception, however, may not be true. Although patients can be upset by the prospect of their sex partners being told of their exposure to an STD, patients generally agree that referring partners is necessary. ${ }^{8} 9$ These findings do not necessarily mean that such patients want their doctors to tell their sex partners-although Golden et al ${ }^{10}$ present evidence that at least some patients have no objections-but it does establish that patients accept that someone has to do so.

The three different forms of partner notification are linked by the extent to which the diagnosing physician has to maintain contact with patients and their partners over the sensitive topic of sexual behaviour. With patient referral, the topic can be dismissed in a sentence or two; with provider referral, there is the matter of a more extensive interview. Many physicians are uncomfortable talking about sexual behaviour, ${ }^{11}{ }^{12}$ especially with opposite sex patients, ${ }^{13}$ as well as some of the most at-risk patients-adolescents and young adults. ${ }^{14}$ Consequently, the source of some of the imagined distress to the patient-physician relationship may be actually caused by physician discomfort with talking about sex. Consistent with this interpretation of the scales are the results in table 1 showing that physicians felt least comfortable with and least trained to perform provider referral. What is missing from this equation is the extent to which patients genuinely dislike talking to physicians about their sexual behaviours and who are their sex partners. Some evidence suggests that patients are comfortable doing so if their physician is also comfortable. ${ }^{15}$

Perhaps if physicians were more comfortable talking to their patients about sex, especially to those patients with multiple partners, physicians would feel more comfortable with added steps such as eliciting partners' names, and perhaps even with contacting those partners. However, the barriers to provider referral in the United States almost certainly go beyond discomfort and lack of training and need examination of other options, including more effective combinations of the resources of physician practices and health departments. One avenue is to simply work on achieving an optimal case reporting system from all physicians to public sector health departments. Physicians could collect information needed to locate and contact partners and either report it to health departments or even pass it on directly to DIS. DIS and other health department staff in most jurisdictions have heavy workloads and locating information could help alleviate DIS workloads. Alternatively, physicians might also introduce a contract system for patients who wish to contact their partners themselves, as some prefer, ${ }^{16}$ who would then have to agree to do so within an appropriate time frame. This triage approach essentially starts the partner notification process with physicians and transfers difficult cases to health departments or directly to DIS.

Note that embedded within both concepts are the principles of ready contact between physicians and health departments and a full and accurate sexual history from the patient. In the interests of informed consent, the fact that sexual behaviour and partner information could be forwarded to a health department would have to be disclosed to patients. Responses from this survey and previous data suggest that many physicians need training and practice in order to discuss sexual behaviour with their patients, but that they are not averse to moving beyond patient referral alone in principle. ${ }^{17}$

The tasks involved are large, but the end points have some advantages over the current system in the United States. Firstly, it involves the physicians who treat STD in partner notification. Precisely what interventions should be implemented is open to debate and evaluation, but the substantial STD morbidity in the United States suggests the burden of notification needs to be shared beyond DIS, but without relying solely on either patient or provider referral. Secondly, the necessary discussions between physician and patient 
embed the discussion of sexual behaviour where it should be: an integral part of routine health care and something that can be taught and learned. ${ }^{11} 18$ Early evidence that this task can be accomplished is found in Seattle, where King County private physicians collaborate in a joint partner notification and partner delivered medication system. ${ }^{19}$ Finally, a reasonable policy goal for any hybrid system would be to spread costs as much as possible over the large and heterogeneous US healthcare system, including ensuring that any parties (for example, private physicians) who bear upfront costs are compensated for those costs.

In conclusion, results suggest relative antipathy towards provider based referral, with some reasons cohering with evidence based conclusions and some in conflict. These data not only describe the nature of these opinions, but also suggest some avenues for exploring improvements to STD partner notification.

\section{ACKNOWLEDGEMENT}

This research was supported by the Division of STD Prevention, CDC, Contract 200-96-0599.

\section{Authors' affiliations}

M Hogben, J S St Lawrence, J S Leichliter, Division of STD Prevention, Centers for Disease Seattle, WA, USA

D E Montaño, D Kasprzyk, W R Phillips, Battelle Centers for Public Health Research and Evaluation, Seattle, WA, USA

\section{REFERENCES}

1 Centers for Disease Control and Prevention. Sexually transmitted disease surveillance, 2001. Atlanta, GA: Centers for Disease Control and Prevention, 2002.

2 Mathews C, Coetzee N, Zwarenstein M, et al. A systematic review of strategies for partner notification for sexually transmitted diseases, including HIV/AIDS. Int J Sex Transm Dis AIDS 2002;13:285-300.

3 Oxman AD, Scott EAF, Sellors JW, et al. Partner notification for sexually transmitted diseases: An overview of the evidence. Can J Public Health 1994;85(suppl 1):S41-7.
4 Brackbill RM, Sternberg MR, Fishbein M. Where do people go for treatment of sexually transmitted diseases? Fam Plann Perspect 1999;31:10-5.

5 Hammet TM, Kaufman JA, Faulkner A. Sexually transmitted disease prevention in the United States: Integrated evaluation of public and private sector disease reporting and service delivery. CDC 200-93-0633, Phase I Final Report, 1997

6 Department of Health and Human Services. National Center for Health Statistics, data from the National Health Care Survey, 1995: Two parts: 1) National Ambulatory Medical Care Survey, 2) National Hospital Ambulatory Medical Care Survey. Washington, DC: US Government Printing Office, 1997.

7 St Lawrence JS, Montano DE, Kasprzyk D, et al. National survey of US physicians' STD screening, testing, case reporting, clinical management, and partner notification practices. Am J Public Health 2002;92:1784-8.

8 Clarke J. Distressed women take contact tracing seriously. BMJ 2001;323:236.

9 Nuwaha F, Kambugu F, Nsubuga PS. Factors influencing sexual partner referral for sexually transmitted diseases in Uganda. Sex Transm Dis 1999;26:483-9.

10 Golden MR, Hopkins SG, Morris M, et al. Support among persons infected with HIV for routine health department contact for HIV partner notification. J AIDS 2003;32:196-202.

11 Perlman SE, Postlethwaite D, Stump S, et al. Taking a sexual history from and counseling women on teratogenic drugs. J Reprod Med 2001;46/suppl 2): 163-8.

12 Wheat ME, Hyman RB, Devons C, et al. Preventing HIV transmission: behavior and attitudes of medical house staff in a high-prevalence area. Am J Prev Med 1993:9:307-16

13 Lurie N, Margolis K, McGovern PG, et al. Physician self-report of comfort and skill in providing preventive care to patients of the opposite sex. Arch Fam Med 1998;7:134-7.

14 Torkko KC, Gershman K, Crane LA, et al. Testing for chlamydia and sexual history taking in adolescent females: results from a statewide survey of Colorado primary health care providers. Pediatrics 2000;103:E32.

15 Presswell N, Barton D. Taking a sexual history. Australian Family Physician 2000;29:535-9.

16 Gorbach PM, Aral SO, Celum C, et al. To notify or not to notify: STD patients' perspectives of partner notification in Seattle. Sex Transm Dis 2000;27:193-200.

17 Dye TD, Knox KL, Novick LF. Tracking sexual contacts of HIV patients: A study of physician practices. J Public Health Manag Pract 1999;5:19-22.

18 Skelton JR, Matthews PM. Teaching sexual history taking to health care professionals in primary care. Med Educ 2001;35:603-8.

19 Golden MR, Whittington WLH, Handsfield HH, et al. Partner management for gonococcal and chlamydial infection: expansion of public health services to the private sector and expedited sex partner treatment through a partnership with commercial pharmacies. Sex Transm Dis 2001;28:658-65.

If you have a burning desire to respond to a paper published in Sexually Transmitted Infections, why not make use of our "eletters" option?

Log onto the STI website (www.stijournal.com), find the paper that interests you, click on [Abstract] or [Full text], and send your electronic response by clicking on "eletters submit a response".

Providing your letter isn't libellous or obscene, it will be posted within seven days. You can view recent eletters by clicking on "Read eletters" on our homepage.

As before, the editors will decide whether to publish the eletter in a further print issue. 